\title{
MODEL PEMBELAJARAN INOVATIF: "NOVEL" Meningkatkan Berpikir Kritis dan Kreatif dalam Pembelajaran Bahasa Indonesia SMA/SMK
}

\author{
Anisa Syahputri \\ E-mail: anisyah.saputri5145@ student.unri.ac.id \\ Program Studi Pendidikan Bahasa dan Sastra Indonesia, Universitas Riau
}

\section{Pengantar}

\section{KATA PENGANTAR}

Permasalahan pendidik saat ini salah satunya ialah proses pembelajaran yang lemah. Proses pelajarannya umumnya masih berfokus pada guru sebagai sumber utama pengetahuan ( Kadir, 2013). Proses pembelajaran merupakan salah satu kunci untuk mencapai tujuan pendidikan. Kebanyakan siswa menganggap mata pelajaran yang dijelaskan di sekolah itu sulit sehingga tidak jarang seorang siswa sudah terlebih dahulu merasa kurang mampu untuk mempelajarinya ( Sakkashiri, 1991) hal tersebut bisa terus saja terjadi dikarenakan oleh kegiatan pembelajaran yang menggunakan metode teacher centeredyang tidak dapat menarik perhatian siswa karena siswa tidak tertarik dan bosan. Keadaan ini akan merugikan terhadap keberhasilan siswa bila tidak segera dibenahi ( Manalu ddk, 2016). Agar dapat memunculkan semangat belajar dari siswa peran pendidikan di sini ialah meningkatkan kemampuan siswa mencari hubungan konseptual antara pengetahuan yang dimiliki dengan yang dipelajari di dalam kelas. ( Silaban \& Dewi, 2012). Untuk mencapai tujuan ini maka diperlukan suatu tindakan konkret yang efisien berdasarkan pengetahuan dan kemampuan yang dibutuhkan dalam proses pembelajaran, yang dapat menyebabkan terjadinya pergeseran pembelajaran yang membosankan menjadi sangat menarik untuk dipelajari oleh siswa ( Rosalia et Al. 2019 ). 5 Desember 2021

\section{Tindakan yang Dilakukan}

a. Mencari kegiatan pembelajaran yang menyenangkan

b. Mencari solusi apa permasalahan dalam melakukan pembelajaran 


\section{c. Tetap mencari ide-ide yang kreatif untuk memulai pembelajaran.}

\section{Guru}

Guru adalah profesi yang sangat membanggakan. Bagaimana tidak, setiap bangsa terlahir karena jasa para guru. Guru adalah orang yang diteladani dan dimuliakan karena jasa dan ilmunya. Sungguh sangat ironis jika profesi ini dikucilkan, semestinya profesi ini harus dicintai dan dibanggakan. Siapapun orangnya, pejabat ataupun tidak, negeri atau swasta mereka semua terlahir karena jasa para guru. Ini menandakan bahwa guru penting adanya, dan profesi ini sesungguhnya tidak pernah lekang oleh waktu. Tiada guru, sama siapa kita bertanya.

Sebuah ungkapan bijak, 'Kalau ingin melihat kualitas suatu bangsa, lihatlah kualitas gurunya'. Keberadaan guru menjadi penentu kualitas - mutu pendidikan suatu bangsa. Minister of Education, Culture and Science (2013) guru menjadi penentu kualitas pendidikan.Guru mampu memberikan peran dan warna suatu bangsa dalam kontek pelaksanaan pendidikan sehingga patut menjadi perhatian (Mustafa, Hermandra, \& Zulhafizh, 2018). Maka tidaklah keliru, jika dikatakan guru sebagai pengajar berperan mentransformasi pengetahuan dan wawasannya kepada peserta didik, guru sebagai pendidik berusaha menanamkan nilai-nilai luhur kepada peserta didik, dan guru sebagai pemimpin tidak hanya melakukan pengajaran dan pendidikan tapi berusaha menciptakan iklim pendidikan dan pembelajaran yang kondusif dengan penuh tanggung jawabnya.

\section{Sarana Pendukung}
a. Google classroom
b. Google meet
c. WhatsApp.
d. Telegram

Selanjutnya dijelaskan bahwa kompetensi guru tersebut meliputi kompetensi kepribadian, pedagogik, profesional, dan sosial.

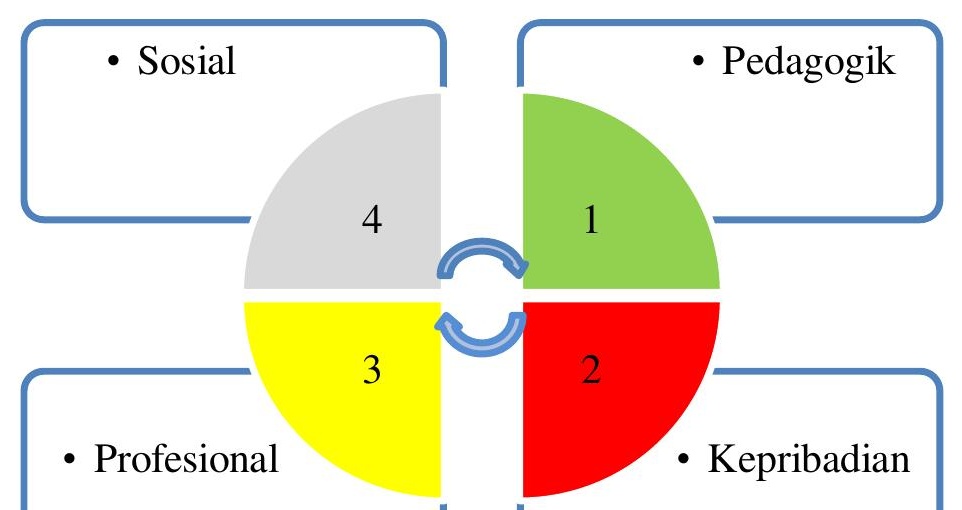




\section{Gambar 1. Kompetensi Guru}

Memahami peserta didik secara mendalam yang meliputi memahami peserta didik dengan memamfaatkan prinsip-prinsip perkembangan kognitif, prinsip-prinsip kepribadian, dan mengidentifikasi bekal ajar awal peserta didik.

Merancang pembelajaran,teermasuk memahami landasan pendidikan untuk kepentingan pembelajaran yang meliputi memahmi landasan pendidikan, menerapkan teori belajar dan pembelajaran, menentukan strategi pembelajaran berdasarkan karakteristik peserta didik, kompetensi yang ingin dicapai, dan materi ajar, serta menyusun rancangan pembelajaran berdasarkan strategi yang dipilih.

Melaksanakan pembelajaran yang meliputi menata latar ( setting) pembelajaran dan melaksanakan pembelajaran yang kondusif.

Merancang dan melaksanakan evaluasi pembelajaran yang meliputi merancang dan melaksanakan evaluasi (assessment) proses dan hasil belajar secara berkesinambungan denga berbagai metode,menganalisis hasil evaluasi proses dan hasil belajar untuk menentukan tingkat ketuntasan belajar (mastery level), dan memamfaatkan hasil penilaian pembelajaran untuk perbaikan kualitas program pembelajaran secara umum.

Mengembangkan peserta didik untuk mengaktualisasikan berbagai potensinya meliputi memfasilitasi peserta didik untuk pengembangan berbagai potensi akademik, dan memfasilitasipeserta didik untuk mengembangkan berbagai potensi nonakademik. . Kompetensi Sosial

Kompetensi Sosial adalah kemampuan guru untuk berkomunikasi dan bergaul secara efektif dengan peserta didik, tenaga kependidikan, orang tua/wali peserta didik, dan masyarakat sekitar.

Bersikap inkulif, bertindak obyektif, serta tidak diskriminatif karena pertimbangan jenis kelamin, agama, ras, kondisi fisik, latar belakang keluarga, dan status sosial keluarga. 
Berkomunikasi secara efektif, empatik, dan santun dengan sesama pendidik, tenaga kependidikan, orang tua dan masyarakat.

Beradaptasi di tempat bertugas di seluruh wilayah RI yang memiliki keragaman social budaya.

Berkomunikasi dengan lisan maupun tulisan.

Kompetensi oleh Spencer dalam Moeheriono (2009:3) didefinisikan sebagai karakteristik yang mendasari seseorang berkaitan dengan efektifitas kinerja individu dalam pekerjaannya atau karakteristik dasar individu yang memiliki hubungan kausal atau sebab-akibat dengan kriteria yang dijadikan acuan, efektif atau berkinerja prima atau superior di tempat kerja atau pada situasi tertentu (competency is an underlying characteristic of an individual that is causally related to criterian referenced effective and or superior performance in a job or situation).

Sudarmanto (2009:45) mengutarakan dalam tulisannya bahwa kompetensi merupakan suatu atribut untuk melekatkan sumber daya manusia yang berkualitas dan unggul. Atribut tersebut adalah kualitas yang diberikan pada orang atau benda, yang mengacu pada karakteristik tertentu yang diperlukan untuk dapat melaksanakan pekerjaan secara efektif. Atribut tersebut terdiri atas pengetahuan, keterampilan, dan keahlian atau karakteristik tertentu. Secara rinci, ada 5 dimensi kompetensi yang harus dimiliki oleh semua individu, yaitu :

Task skills, yaitu keterampilan untuk melaksanakan tugas-tugas rutin sesuai dengan standar ditempat kerja.

Task management skills, yaitu keterampilan untuk mengelola serangkaian tugas yang berbeda yang muncul dalam pekerjaan.

Contigency management skills, yaitu keterampilan mengambil tindakan yang cepat dan tepat bila timbul suatu masalah dalam pekerjaan

Job role environment skills, yaitu keterampilan untuk bekerja sama serta memelihara kenyamanan lingkungan kerja.

Transfer skill, yaitu keterampilan untuk beradaptasi dengan lingkungan kerja baru.

\section{Tindakan Solutif}
a. Jika Google Classroom tidak Bisa Dimaksimalkan
b. Jika WhatsApp tidak Bisa Dimaksimalkan
c. Jika google meet tidak Bisa Dimaksimalkan
d. Jika telegram tidak bisa Dimaksimalkan 


\section{Simpulan}

Profesi guru adalah pekerjaan mulia, Kesimpulan. Pada prinsipnya profesionalisme guru adalah guru yang dapat menjalankan tugasnya secaraprofesional, yang memiliki ciri-ciri antara lain:Ahli di Bidang teori dan Praktek Keguruan. Guru profesional adalah guru yang menguasaiilmu pengetahuan yang diajarkan dan ahli mengajarnya (menyampaikannya). Dengan katalain guru profesional adalah guru yang mampu membelajarkan peserta didiknya tentangpengetahuan yang dikuasainya dengan baik.Senang memasuki organisasi Profesi Keguruan. Suatu pekerjaan dikatakan sebagai jabatanprofesi salah satu syaratnya adalah pekerjaan itu memiliki organiasi profesi dan anggota-anggotanya senang memasuki organisasi profesi tersebut. Guru sebagai jabatan profesionalseharusnya guru memiliki organisasi ini. Fungsi organisasi profesi selain untuk menlindungikepentingan anggotanya juga sebagai dinamisator dan motivator anggota untuk mencapaikarir yang lebih baik (Kartadinata dalam Meter, 1999). Konsekuensinya organisasi profesiturut mengontrol kinerja anggota, bagaimana para anggota dalam memberikan pelayananpada masyarakat. PGRI sebagai salah satu organisasi guru di Indonesia memiliki fungsi.Menyatukan seluruh kekuatan dalam satu wadah,Mengusahakan adanya satu kesatuan langkah dan tindakan,Melindungi kepentingan anggotanya,Menyiapkan program-program peningkatan kemampuan para anggotanya,

\section{Referensi}

Link google scholar https://scholar.google.co.id/citations?user=tgwzJWAAAAAJ\&hl=id\&oi=ao

Pembelajaran masa Covid-19 1

https://disdikpora.bulelengkab.go.id/informasi/detail/artikel/55-masa-pandemi-pembelajaran-dimasa-pandemi-covid-19

Anisa Syahputri: Membina Aktivitas Belajar Mahasiswa di Perguruan Tinggi Melalui Metode teknologi komunikasi. Seperti WhatsApp, email dan lainnya.

Jurnal Kependidikan: Jurnal Hasil Penelitian dan Kajian Kepustakaan di Bidang Pendidikan, Pengajaran dan Pembelajaran, 6(3), 502-511.

Pembelajaran masa Covid-19 2 https://ayogurubelajar.kemdikbud.go.id/seri-pandemi/ 
Anisa Syahputri: seorang guru harus mempunyai rasa kepercayaan diri terhadap dirinya.

Mampu untuk meningkatkan pembelajaran kepada muridnya.

Motivasi dan hasil belajar

Mustafa, M. N., Hermandra, Zulhafizh, \& Hermita, N. (2018). The Significance of Language Motivations Learning: Correlation Analysis. Advanced Science Letters, 24(11), 80808083.

Media pembelajaran https://jes.ejournal.unri.ac.id/index.php/JES/article/download/6972/6177

Mustafa, M. N., Hermandra, \& Zulhafizh. (2019). Teachers' Strategies to Design Media to Implement Communicative Leaning in Public Schools. Journal of Educational Sciences, $3(1), 13-24$.

Membangun profesionalitas guru http://bksptnbarat.org/wpcontent/uploads/2018/02/PROCEEDINGS-SEMIRATA-1.pdf

Mustafa, M. N., \& Zulhafizh. (2017). Building the Professionalism of Teachers as an Effort to Improve Education. In Husein, R, et al (Eds.), International Seminar and Annual Meeting 2017 Fields of Linguistics, Literature, Arts, and Culture, Medan, 449. 


\section{*Data Penulis}

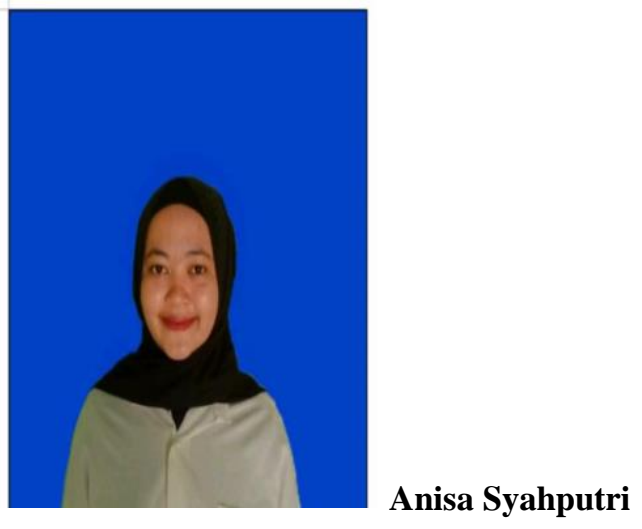

lahir di Cerenti , 17 Desember 2001. Pada tahun akademik 2020 - 2024 Ia melanjutkan studi pada strata satu Jurusan Pendidikan Bahasa dan Seni di Program Studi Pendidikan Bahasa dan Sastra Indonesia FKIP Universitas Riau melalui jalur PBUD................. prestasi karya dihasilkannya yaitu pernah menulis puisi dan bermain badminton mendapatkan juara 3 .

Kontak:

Hp/WA : 0852579425

Email : anisyah.saputri5145@student.unri.ac.id 